\title{
Revision of a Widened Scar Using Dermal Splinting Technique
}

\author{
Sik Namgoong, Jae-A Jung, \\ Deok-Yeol Kim, Seong-Ho Jeong, \\ Seung-Kyu Han, Woo-Kyung Kim, \\ Eun-Sang Dhong \\ Department of Plastic Surgery, Korea \\ University Guro Hospital, Korea \\ University College of Medicine, Seoul, \\ Korea
}

No potential conflict of interest relevant to this article was reported.

\begin{abstract}
Background Scar revision is a fundamental technique in the field of plastic and reconstructive surgery. Methods using local flaps, such as a Z-plasty, W-plasty, or geometric broken-line closure, have been used for scar revision. Widening of scars is a frustrating event that most plastic surgeons have encountered. Several therapeutic modalities have been proposed, but frequently, the result is disappointing. We describe our experience with the use of a dermal splinting technique for scar revision.

Methods We propose a technique by which tension on the wound is applied by tough scar tissue instead of the suture line, thereby reducing the incidence of postoperative widening. This technique was used to treat 21 nonburn scars that had widened:5 scars were facial ( 3 patients), 8 were on the extremities ( 6 patients), and 8 were on the torso ( 5 patients). All scars were at least 4 months old. The operations were performed between January 2003 and December 2012; follow-up was 9 to 24 months.

Results Only one scar widened during the follow-up period. Overall, satisfaction with scar appearance and surgery was assessed with a visual analog scale (VAS). Mean patient satisfaction was $8.1 \pm 0.5$.

Conclusions We recommend this technique in dealing with widened scars in highly tensile areas during revision surgery.
\end{abstract}

Keywords Cicatrix, Sutures, Cosmetic techniques

\section{INTRODUCTION}

Scar revision is a fundamental technique in the field of plastic and reconstructive surgery. There are many types of scars, such as linear, wide, smooth, uneven, depressed, and hypertrophic. Surgeons have used different local flaps or inventive suture techniques for scar camouflage. However, there is no unique solution for scar camouflage. Different approaches $[1,2]$ have been used to deal with this problem, including intralesional corticosteroids [3], compression therapy, laser treatment, irradiation, cryotherapy, silicone applica-

Received: Jun 5, 2015 Revised: Jun 19, 2015 Accepted: Jun 19, 2015 Correspondence: Eun-Sang Dhong Department of Plastic Surgery, Korea University Guro Hospital, 148 Gurodong-ro, Guro-gu, Seoul 152-703, Korea. E-mail: prsdhong@kumc.or.kr

Copyright @ 2015 The Korean Society for Aesthetic Plastic Surgery.

This is an Open Access article distributed under the terms of the Creative Commons Attribution Non-Commercial License (http://creativecommons.org/licenses/by-nc/3.0/) which permits unrestricted non-commercial use, distribution, and reproduction in any medium, provided the original work is properly cited. www.e-aaps.org tions [4-6], and even chemotherapy. Numerous procedures that have been described for the treatment of this condition emphasize the discouraging fact that no one procedure has been entirely satisfactory. Such treatments might succeed in flattening the hypertrophic scar, but do very little to overcome the problem of scar widening.

Widened scars are usually conspicuous on the extremities and torso. There are many reports of revision or correction in these areas, but the results are discouraging.

The degree of widening depends on many parameters, such as the direction of the wound, approximate distance to relaxed skin tension lines (RSTL), skin loss, and condition of the adjacent tissue. Most of all, orientation of the final scar is critical in the treatment of widened scars. Complex tissue-shifting techniques such as Zplasty and W-plasty are frequently used for scars of the face and web spaces. But scars of the extremities located on the torso and the dorsum of joint areas are apt to widen because of inherent "skin tension." These scars can be excised, and if possible, widely undermined and closed with many tight intradermal sutures. Longer retaining sutures are important to reduce mechanical creep, and many 

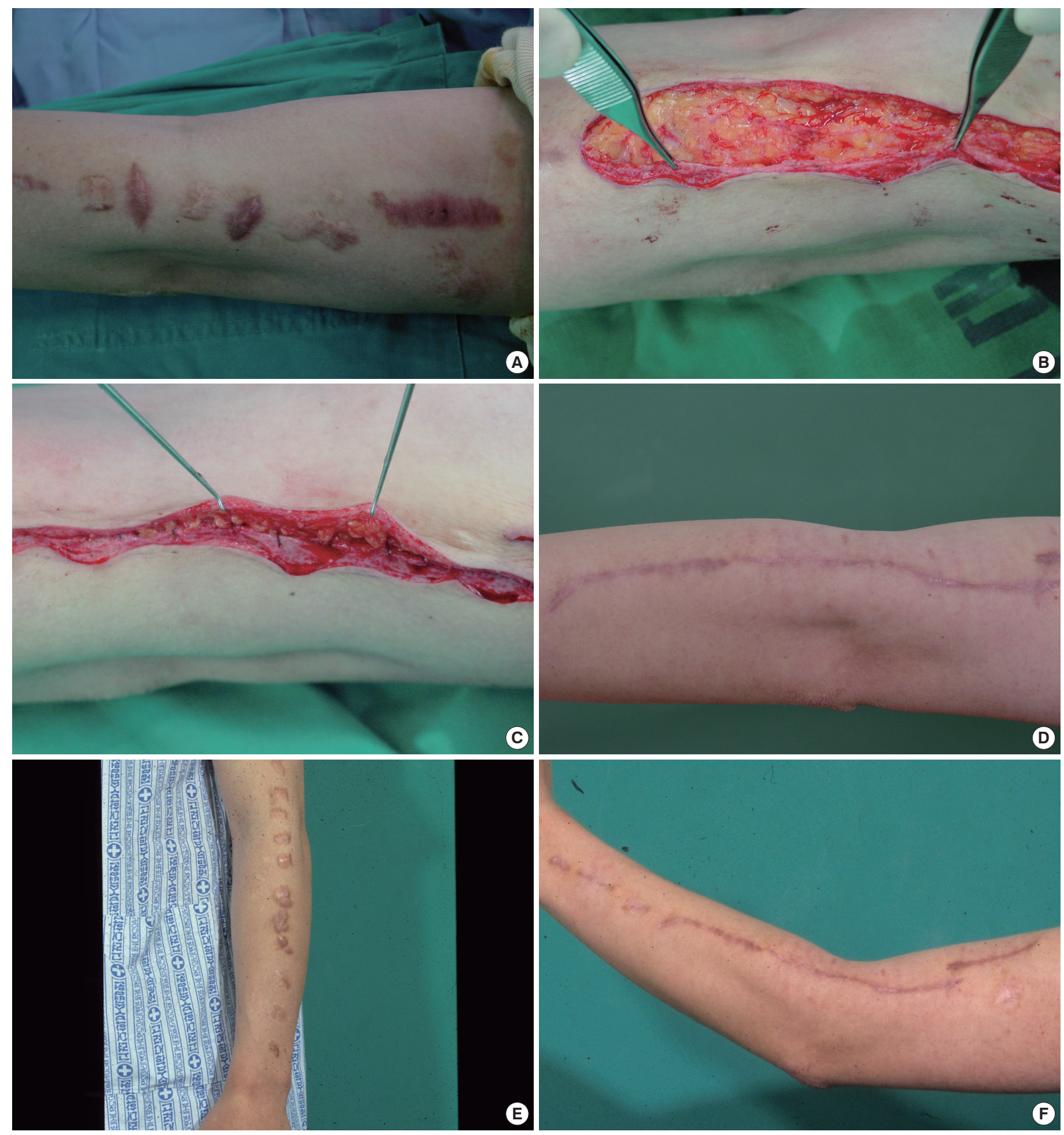

Fig. 1. A 31-year-old man complained of a widened postoperative scar on his left forearm. We excised the epithelium of the scar, leaving an exposed dermal sheet. The dermal sheet component was advanced under the opposite side, to the depth of the undermining, and was fixed in place with several buried interrupted sutures, putting most of the wound tension at the subcutaneous level and bringing the two opposing edges together without tension at the surface. (A) Widened scar on the left forearm, which had been revised twice at other clinics. (B) A dermal platform of scar tissue is prepared at one margin of the incision. (C) Buried sutures between the edge of the underlying dermal flap and the deep undersurfaces of the overlying skin flap. (D) Results at 8 weeks postoperatively. (E and F) Pre- and 8-weeks postoperative photos. 
methods that eliminate this tension have involved long-term skin taping and short-term horizontal mattress sutures [7]. Some authors advocate the placement of nonabsorbable buried sutures such as nylon or polypropylene. All techniques are based on the idea that stretching occurs mostly at the suture site, so additional coaptation of permanent dermal sutures will help wounds not to spread.

\section{METHDOS}

Between January 2003 and December 2012, this procedure was used for 21 wide scars despite having been revised 2 to 4 times (mean, 2.6 times), with the last revision done 4 to 24 months (mean, 9 months) before intervention. There were 5 facial scars in three patients, 8 scars located on the extremities of six patients, and 8 scars located on the torso of five patients. All scars initially resulted from traumatic injuries, with a sharp object being the cause in 17 cases (81\%) and blunt objects in 4 cases (19\%). Burn scars were excluded from this study because of the effects of burn blister fluid on fibroblast contraction, which could possibly alter the results.

There are many techniques utilizing scar beds for correction of depressed or retracted scars. Instead of excising the scar tissue completely, thin layers of epidermis and dermis are removed and the scarred subcutaneous tissue is buried under the sutured edges of the operative wound [8-10]. Since scar tissue is much tougher than the adjacent healthy dermis and stretches minimally under tensile forces, we adopted the scar bed as an additional coaptating material. Multi-layered dermal sutures enforced the wound closure (Fig. 1).

\section{Surgical technique}

First, an incision is made on one margin of the scar and deepened, exposing the subcutaneous fatty tissue. On the opposite side, a partial incision is made only into the mid-dermal layer, identifying dermal spotting. Leaving an appropriate width of scar tissue along the incompletely incised margin, the remaining scar is removed completely (Fig. 2). The attached scar is then de-epithelialized, leav- ing a flat dermal platform (Fig. 3C). The skin and dermal edges are undermined subcutaneously, keeping minimal subcutaneous fat, to make the skin and dermal flaps on each side. The skin flap is draped over the dermal platform of the dermal flap when the two edges of the incision are approximated. When we undermine the skin flap area, we preserve minimal subcutaneous fat for the purpose of saving the vascularity of the subdermal plexus area.

Buried interrupted sutures are made using 2-0 or 3-0 Vicryl between the edge of the underlying dermal flap and the deep undersurfaces of the overlying skin flap (Fig. 3D). When the undersurfaces of the skin flap are sutured, skin dimpling is usually noted, revealing that deep dermal portions of the skin flap are retracted by the sutures. Additional buried sutures are made repeatedly between the dermal platform and the undersurfaces of the skin flap (Fig. 1C). Along the edge of the overlying skin flap, the undersurface is defatted slightly to reduce the likelihood of later deformities. Final buried sutures are made, either interrupted or continuous, using 4-0 polydioxanone (PDS) between the dermis of the approximated skin flap and the dermis of the partially incised edge. The sutures are tied until the tissue is adequately re-approximated, but not as hard as possible to avoid necrosis of the area. The skin is closed using 5-0 nylon interrupted sutures, especially where deformities are conspicuous. We performed skin sutures with 6-0 or 7-0 nylon for facial scars. Postoperatively, no topical treatments were applied to the repaired scar.

The technique can be outlined simply in four steps:

1. The epithelium is dissected from the scar, leaving the dermal component intact (Fig. 4A).

2. Along one side of the scar, an incision is made through the dermis into the subcutaneous tissue. Then, on the bias, this edge is undermined laterally with a scalpel-slightly more than the width of the scar (broken line in cross-section; Fig. 4B).

3. The dermal scar, still attached to the opposite side, is undermined as a sheet until reaching the level of the opposite normal skin edge. At this point, undermining is carried deeper


Fig. 2. (A) A 16-year-old woman complained of a widened postoperative scar in the left clavicle area. Preoperative photo of the postoperative scar in the left clavicle area. (B) Intraoperative view of de-epithelialized scar tissue and advancement of the skin flap over the dermal platform. (C) Postoperative photo at 2-month follow-up. 

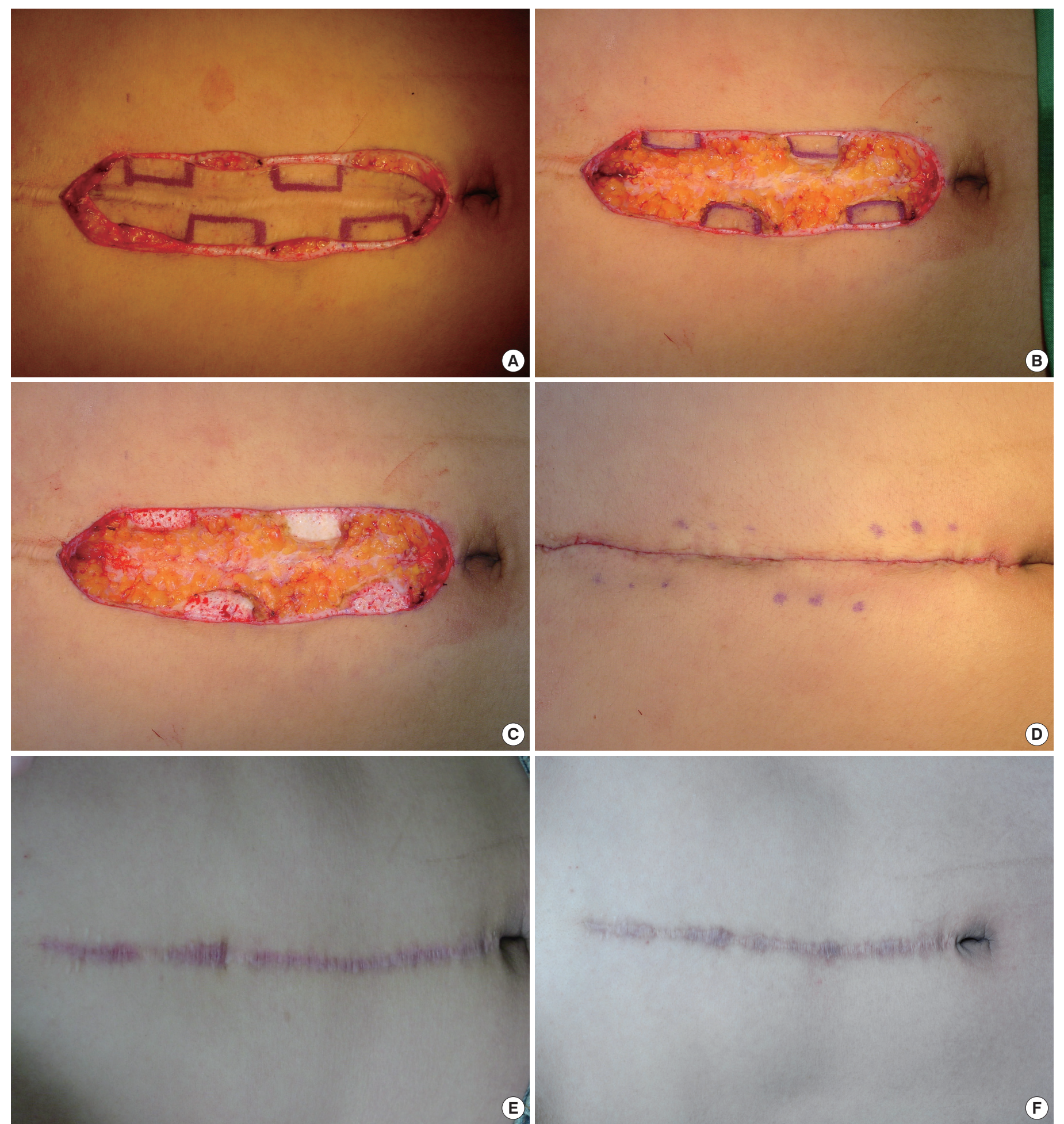

Fig. 3. (A) A 26-year-old man complained of a widened postoperative scar on the abdomen. A dermal platform area to be reserved was designed. (B) The epithelium from the scar was excised, leaving an exposed dermal sheet. (C) Intraoperative photograph demonstrating how deepithelialization is done. (D) Immediate postoperative photograph demonstrating the advancement of the skin flap over the dermal platform. (E) Postoperative photo at 13-month follow-up. (F) Postoperative photo at 24-month follow-up. 


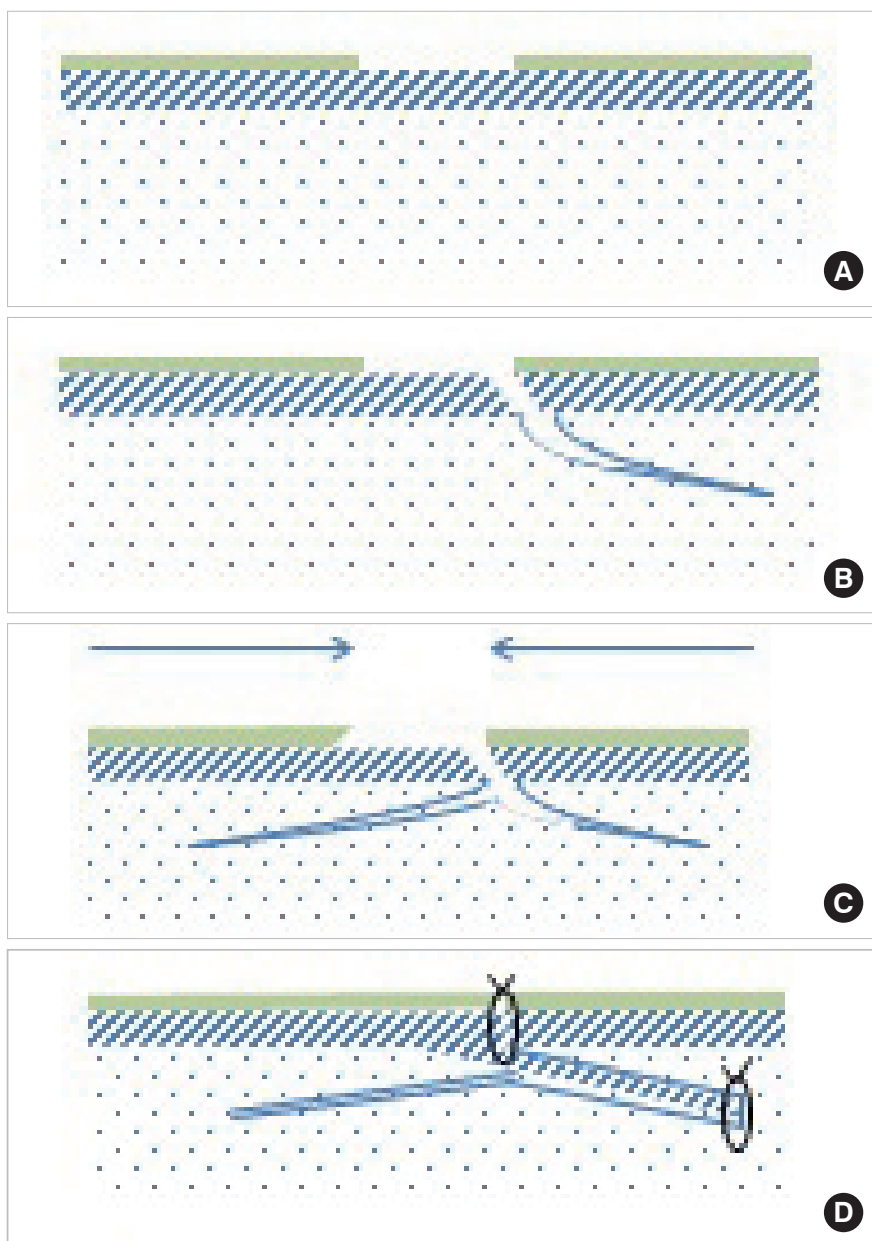

Fig. 4. (A) The epithelium from the scar was excised, leaving an exposed dermal sheet. (B) A vertical incision was made through one edge of the dermal sheet, and undermining was done laterally on that side at a distance slightly more than the width of the scar. (C) The dermal scar sheet was undermined for a greater distance in the opposite direction. An incision on the bias was made at the opposite edge and carried partly through the dermis to provide an edge equal in length to the opposite side. (D) The dermal scar sheet was advanced and sutured subcutaneously at the edge of the undermining on the opposite side, taking the tension off the new closure, which is now sutured in its separate and staggered location.

into the subcutaneous tissue, which produces a sheet of scar tissue extending from the end of the free edge. Along the point where the denuded dermis joins the normal skin, an incision on the bias is made to a safe depth (Fig. 4C).

4. The scar sheet is advanced across the wound and under the opposite side, to the depth of the undermining; it is fixed there with several buried interrupted sutures. This process results in most of the wound tension existing at the subcutaneous level and brings the two opposing skin edges together without tension at the more superficial level (Fig. 4D).
Table 1. Scar assessment results at 14-week follow-up

\begin{tabular}{|c|c|c|c|c|c|c|c|}
\hline & \multirow{2}{*}{$\begin{array}{l}\text { No. of } \\
\text { scars }\end{array}$} & \multirow{2}{*}{$\begin{array}{l}\text { Previous } \\
\text { revisions }\end{array}$} & \multirow{2}{*}{$\begin{array}{l}\text { VAS } \\
\text { score }\end{array}$} & \multicolumn{4}{|c|}{ Complications } \\
\hline & & & & $\begin{array}{l}\text { Dehis- } \\
\text { cence }\end{array}$ & $\begin{array}{l}\text { Infec- } \\
\text { tion }\end{array}$ & $\begin{array}{c}\text { Hema- } \\
\text { toma }\end{array}$ & $\begin{array}{c}\text { Sero- } \\
\text { ma }\end{array}$ \\
\hline \multicolumn{8}{|l|}{ Facial } \\
\hline \multirow[t]{3}{*}{ Sharp injuries } & 2 & 2 & 8.5 & 0 & 0 & 0 & 0 \\
\hline & 1 & 3 & 8.0 & 0 & 0 & 0 & 0 \\
\hline & 0 & 4 & - & - & - & - & - \\
\hline \multirow[t]{3}{*}{ Blunt injuries } & 1 & 2 & 8.5 & 0 & 0 & 0 & 0 \\
\hline & 0 & 3 & - & - & - & - & - \\
\hline & 1 & 4 & 8.0 & 0 & 0 & 0 & 0 \\
\hline Extremities & 4 & 2 & 8.5 & 0 & 0 & 0 & 0 \\
\hline \multirow{2}{*}{ Sharp injuries } & 2 & 3 & 8.5 & 0 & 0 & 0 & 0 \\
\hline & 1 & 4 & 8.0 & 0 & 0 & 0 & 0 \\
\hline \multirow[t]{3}{*}{ Blunt injuries } & 1 & 2 & 6.0 & 0 & 0 & 0 & 0 \\
\hline & 0 & 3 & - & - & - & - & - \\
\hline & 0 & 4 & - & - & - & - & - \\
\hline \multicolumn{8}{|l|}{ Torso } \\
\hline \multirow[t]{3}{*}{ Sharp injuries } & 3 & 2 & 8.0 & 0 & 0 & 0 & 0 \\
\hline & 2 & 3 & 9.0 & 0 & 0 & 0 & 0 \\
\hline & 2 & 4 & 9.3 & 0 & 0 & 0 & 0 \\
\hline \multirow[t]{3}{*}{ Blunt injuries } & 1 & 2 & 3.0 & 1 & 0 & 0 & 0 \\
\hline & 0 & 3 & - & - & - & - & - \\
\hline & 0 & 4 & - & - & - & - & - \\
\hline
\end{tabular}

Values are presented as numbers.

VAS, visual analog scale.

\section{Scar assessment}

Scar assessment was carried out at postoperative week 14. Subjective scar assessment was performed via the visual analog scale (VAS) [11]. All patients were asked to rate their overall satisfaction with the scars and the surgery using the VAS, with 0 being the worst and 10 being the best aesthetic result. Patients were asked to report the degree of satisfaction with the appearance of the scar. The VAS consisted of a $10 \mathrm{~cm}$ line that was divided into ratings of "marked aggravation" $(0-2 \mathrm{~cm})$, "worse" $(2-4 \mathrm{~cm})$, "unchanged" $(4-6 \mathrm{~cm})$, "slight improvement" (6-8 cm), and "marked improvement" (8-10 cm).

\section{RESULTS}

Twenty-one patients were treated between January 2003 and December 2012 using this dermal splinting technique. The follow-up period ranged from 9 to 24 months (mean, 13.2 months), and in all cases except one, there was no widening of the scars. No complications were encountered in the postoperative period, except in one patient who suffered wound dehiscence and required secondary sutures. During the first 6 to 8 weeks after surgery, the scars were red and firm, but in time, they blanched and softened. Patients were asked to record their overall satisfaction with the procedure and outcomes on a VAS. Mean patient satisfaction was 8.1 \pm 0.5 . Table 1 summarizes the condition of the scars before surgery and 
the postoperative results. Furthermore, we ascertain that, with proper patient selection, this technique renders excellent results in patients who do not want scar lengthening using Z-plasty, or whose scars on their extremities or torso are located across the RSTL at right angles.

\section{DISCUSSION}

The techniques used for scar revision may differ from scar to scar and from patient to patient. The widening of scars is a frustrating problem that frequently follows wound suturing. Particularly, widened scars in joint areas or on the torso leave poor aesthetic results, and require additional scar lengthening by Z-plasty. Distracting mechanical forces applied to the healing wounds before collagen maturation may result in such untoward outcomes.

As mechanical creep occurs mostly at wound margins, tighter closure in the deep dermis will help during revisions in highly tensile areas. Scar beds are tougher that adjacent tissue, so multiple deep dermal sutures between a dermal platform of the dermal flap and the subdermis of the skin flap will act like a longstanding internal splint. Although wounds may spread to some extent at the partially incised margin, the dermis that was preserved continuously will be much stronger than routine interrupted sutures. Inversion of wound margins, which is another enemy of scar revision [12], never takes place when this technique is used. Deformities of the wound margin occur irregularly but disappear spontaneously. If this exists, dermabrasion is another solution for yielding better results.

\section{CONCLUSION}

Dermal splinting for the revision of a widened scar in highly tensile areas is described. A dermal flap of scar tissue is prepared at one edge of the incision, and is sutured to the opposite subdermis. The skin flap is then draped over the dermal platform of the dermal flap on the other side. In highly tensile areas, such as extremities and the torso, this longstanding dermal splint would afford better results.

\section{PATIENT CONSENT}

Patients provided written consent for the use of their images.

\section{REFERENCES}

1. Nicolai JP, Bos MY, Bronkhorst FB, et al. A protocol for the treatment of hypertrophic scars and keloids. Aesthetic Plast Surg 1987;11:29-32.

2. Darzi MA, Chowdri NA, Kaul SK, et al. Evaluation of various methods of treating keloids and hypertrophic scars: a 10-year follow-up study. Br J Plast Surg 1992;45:374-9.

3. Tang YW. Intra- and postoperative steroid injections for keloids and hypertrophic scars. Br J Plast Surg 1992;45:371-3.

4. Ahn ST, Monafo WW, Mustoe TA. Topical silicone gel: a new treatment for hypertrophic scars. Surgery 1989;106:781-6.

5. Ahn ST, Monafo WW, Mustoe TA. Topical silicone gel for the prevention and treatment of hypertrophic scar. Arch Surg 1991;126:499-504.

6. Quinn KJ. Silicone gel in scar treatment. Burns Incl Therm Inj 1987;13 Suppl:S33-40.

7. Borges AF. Principles of scar camouflage. Facial Plast Surg 1984;1:18190.

8. Lewin ML, Keunen HF. Revision of the posttracheotomy scar. Correction of the depressed, retracted scar. Arch Otolaryngol 1970;91:395-7.

9. Harahap M. Revision of a depressed scar. J Dermatol Surg Oncol 1984; 10:206-9.

10. Wilson AM. Widening of scars: foe coaxed into a friend? The Millard technique revisited. Plast Reconstr Surg 2000;106:1488-93.

11. Duncan JA, Bond JS, Mason T, et al. Visual analogue scale scoring and ranking: a suitable and sensitive method for assessing scar quality? Plast Reconstr Surg 2006;118:909-18.

12. Zide MF. Scar revision with hypereversion. J Oral Maxillofac Surg 1996; 54:1061-7. 